\title{
CHARACTERISATION OF STROMA MEMBRANES FROM Zea mays L. CHLOROPLASTS
}

\author{
by \\ ROBERTO BASSI ${ }^{1}$, GIORGIO GIACOMETTI ${ }^{1)}$ and DAVID J. SIMPSON \\ Department of Physiology, Carlsberg Laboratory, \\ Gamle Carlsberg Vej 10, DK-2500 Copenhagen Valby \\ and \\ 1)Dipartimento di Biologia, Università di Padova, \\ Via Loredan 10, 35100 Padova, Italy
}

Keywords: Chlorophyll-proteins, fluorescence emission spectroscopy, light-harvesting chlorophyll $a / b$-protein II, photosystem I, polypeptide composition, thylakoids

Stroma lamellae were isolated from dark-adapted maize seedling leaves by mechanical disruption of isolated, stacked thylakoids. Their chlorophyll-protein composition was analysed by non-denaturing SDS-PAGE and revealed the presence of $\mathrm{Chl}_{a}-\mathrm{Pl}$, LHCI-730, LHCI-680 and a small amount of LHCII. Also present were the chlorophyll-protein complexes $\mathrm{Chl}_{a}-\mathrm{P} 1^{*}, \mathrm{LHCl}-730^{*}$ and $\mathrm{LHCII}^{* *}$. This is consistent with the model proposed for PSI based on detergent isolation, and confirms the presence of LHCI-680 in PSI in situ. Re-electrophoresis of the chlorophyll-protein bands under denaturing conditions, revealed three low molecular weight PSI polypeptides which were always found associated with LHCI-730. Quantitation of PSII polypeptides by immuneblot assay showed that stroma lamellae contained 30 times less than grana lamellae on a chlorophyll basis. This indicates that most of the LHCII was associated with PSI, but the oligomeric form (LHCII**) in stroma lamellae was stable only in the presence of $\mathrm{Mg}^{++}$, in contrast to $\mathrm{LHCII}^{* *}$ from granal membranes. This is correlated with the absence of a $26 \mathrm{kD}$ LHCII polypeptide from stroma lamellae.

\section{INTRODUCTION}

The primary processes of photosynthesis occur in the internal membranes, or thylakoid system, of chloroplasts. The thylakoids are morphologically differentiated into appressed regions (grana lamellae) and non-appressed regions (strcma lamellae), which have very different appearances when examined by freeze-fracture electron microscopy (25). Early work using digitonin fractionation or mechanical disruption (23), showed that isolated grana and stroma lamellae also have different properties and polypeptide compositions. More recently, it has been shown that the composition of these two types of membranes is very different, giving rise to the concept of extreme lateral heterogeneity of the two photosystems (3). It is now generally accepted that all PSI and $\mathrm{CF}_{1}$ is located in stroma

\footnotetext{
Abbreviations: $\mathrm{CF}_{1}=$ extrinsic part of chloroplast coupling factor; $\mathrm{Chl}=$ chlorophyll; $\mathrm{EFs}=$ endoplasmic fracture face of stacked thylakoids; $\mathrm{kD}$ = kilodaltons; $\mathrm{LHCI}=$ light harvesting chlorophyll-protein of PSI; LHCII = light harvesting chlorophyll-protein of PSII; PAGE = polyacrylamide gel electrophoresis; PSI = photosystem I; PSII = photosystem II; SDS = sodium dodecyl sulphate.
} 
lamellae, while most of the PSII, along with its antenna LHCII and water splitting complex, is located in the appressed grana membranes $(2,3$, $15,27)$. Such fractionation experiments have been independently confirmed by immunogold labelling of thin sections $(17,29,30)$ and freezefracture electron microscopy of mutants $(25$, 26).

The lateral segregation of the two photosystems is the basis for the isolation and purification of functional PSII $(3,10,11)$ from appressed membranes, although PSI is usually isolated by Triton X-100 treatment of destacked thylakoids $(8,9,22)$. The use of a detergent raises the possibility of the selective extraction of some components, or a rearrangement, such as the loss of cytochrome $f / b 6$ from appressed thylakoids (11) or the induced association of LHCII with PSI (9). The present paper reports the characterisation of the chlorophyll-proteins in maize stroma lamellae isolated without detergent, and discusses the structure of PSI with reference to a recently proposed model (9).

\section{MATERIAL AND METHODS}

\subsection{Plant material}

Maize seeds (Zea mays L. cv. DeKalb DF 28) were soaked in water for $24 \mathrm{~h}$ and grown in a vermiculite/soil mixture under glasshouse conditions in summer. High light conditions were maintained by supplementing daylight with mercury vapour lamps.

\subsection{Light adaptation and thylakoid isolation}

Three-week old maize plants were placed in the dark for $1 \mathrm{~h}$ and leaves were rapidly harvested and immediately ground up in a homogeniser with replaceable razor blades (18), using 10 volumes of ice-cold buffer ( $350 \mathrm{~mm}$-sorbitol, 50 mM-Hepes, $\mathrm{pH} 7.5,10 \mathrm{~mm}-\mathrm{MgCl}_{2}, 1 \mathrm{~mm}$-ascorbate and $10 \mathrm{~mm}-\mathrm{NaF}$ ). After $4 \times 5 \mathrm{~s}$ full speed bursts, mesophyll chloroplasts were obtained by filtering the resulting slurry through two layers of $30 \mu \mathrm{m}$ nylon mesh and centrifuging for 10 $\min$ at $1500 \times \mathrm{g}(4)$. The pellet was resuspended in $50 \mathrm{~mm}$-Hepes, $\mathrm{pH} 7.5,10 \mathrm{~mm}-\mathrm{MgCl}_{2}, 1$ $\mathrm{mm}$-ascorbate and $10 \mathrm{~mm}-\mathrm{NaF}$, and left to stand for $10 \mathrm{~min}$ at $0{ }^{\circ} \mathrm{C}$. After $10 \mathrm{~min}$ centrifugation at $20,000 \times \mathrm{g}$, the pellet was resuspended in the above buffer to a chlorophyll concentration of 2 $\mathrm{mg} \cdot \mathrm{ml}^{-1}$.

\subsection{Isolation of stroma and grana lamellae}

Thylakoids were disrupted by passing them three times through a French pressure cell operated at $1300 \mathrm{psi}$ with a flow rate of $8 \mathrm{ml} \cdot \mathrm{min}^{-1}$. The suspension was then centrifuged for $30 \mathrm{~min}$ at $40,000 \times g$ and the upper three-quarters of the supernatant was carefully transferred to ultracentrifuge tubes with a pipette, as described in (15). The stroma lamellae were pelleted at $110,000 \times \mathrm{g}$ for $30 \mathrm{~min}$ and resuspended in 200 mM-sucrose, 20 mM-Hepes, $\mathrm{pH}$ 7.5, $5 \mathrm{~mm}-\mathrm{Mg}$ $\mathrm{Cl}_{2}, 10 \mathrm{~mm}-\mathrm{NaF}$ to a final chlorophyll concentration of $1.3 \mathrm{mg} \cdot \mathrm{ml}^{-1}$. Aliquots were also resuspended in a modified medium, containing 10 mM-EDTA and lacking $\mathrm{MgCl}_{2}$ and NaF. Appressed grana lamellae were isolated according to the method of (10).

\subsection{Electrophoresis}

SDS-PAGE was performed under non-denaturing conditions at $4{ }^{\circ} \mathrm{C}$ as previously described (8), involving the use of octyl glucoside and $40 \%$ glycerol in the solubilisation buffer, together with $10 \%$ glycerol in the gel to stabilise non-covalent associations between chlorophyll and protein, and between chlorophyll-proteins. SDS-PAGE under denaturing conditions was carried out in the presence of $6 \mathrm{M}$-urea and gels were fixed in methanol/acetic acid/water $(2: 2: 0.4)$ and stained with Coomassie Brilliant blue (4).

\subsection{Spectroscopy}

Low temperature fluorescence emission and excitation spectra were recorded with a PerkinElmer MPF44 spectrofluorimeter equipped with a low temperature attachment. Samples were diluted to $5 \mu \mathrm{g} \mathrm{chl} \cdot \mathrm{ml}^{-1}$, loaded into glass capillary tubes and frozen in liquid nitrogen. Spectra were not corrected. Absorption spectra were recorded with a Perkin-Elmer Lambda 5 spectrophotometer. 


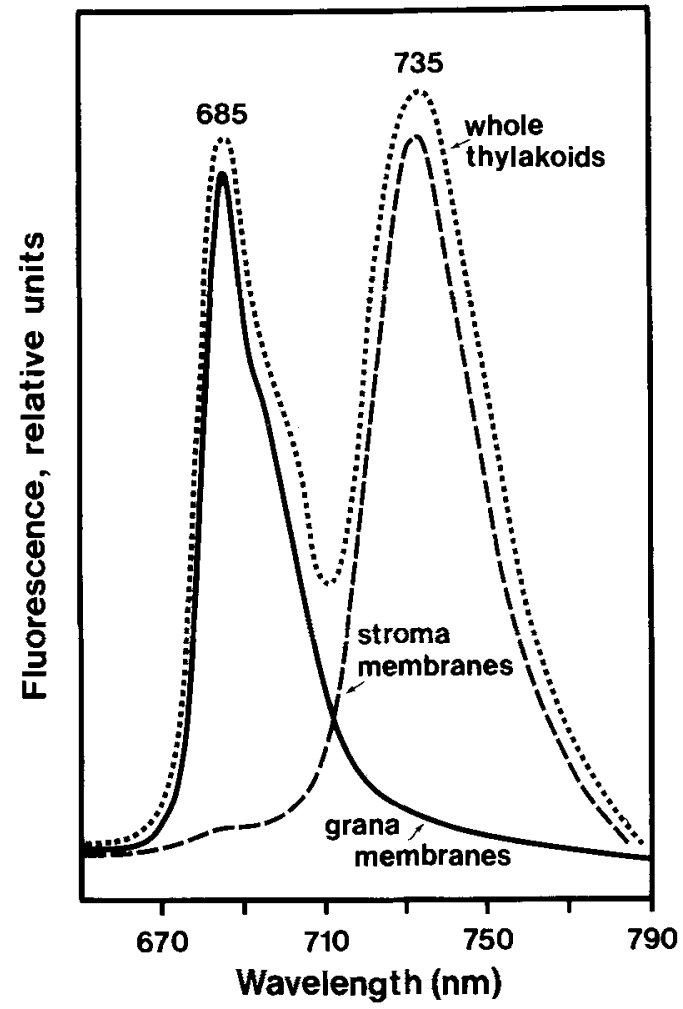

Figure 1. Low temperature $(77 \mathrm{~K})$ fluorescence emission spectra of stroma membranes compared with grana membranes and whole thylakoids. Chlorophyll concentration was $5 \mu \mathrm{g} \cdot \mathrm{ml}^{-1}$. Excitation was at $445 \mathrm{~nm}$ with a $6 \mathrm{~nm}$ slit, and emission was measured through a $3 \mathrm{~nm}$ slit. There is almost no $685 \mathrm{~nm}$ emission in the stroma membrane preparation.

\subsection{Immunology}

PSII membranes (10) were used to raise polyclonal antibodies from rabbits (5). These antibodies were used in immuneblot assays (17) to quantify the amount of PSII polypeptides in stroma lamellae using ${ }^{125}$ I-labelled protein $\mathrm{A}$.

\section{RESULTS}

The low temperature fluorescence emission spectra of mechanically isolated stroma lamellae and appressed grana membranes are compared in Figure 1. The spectrum of whole thylakoids is characterised by peaks at 685 and $695 \mathrm{~nm}$, which have been assigned to PSII and LHCII, and $735 \mathrm{~nm}$ resulting from PSI. Since

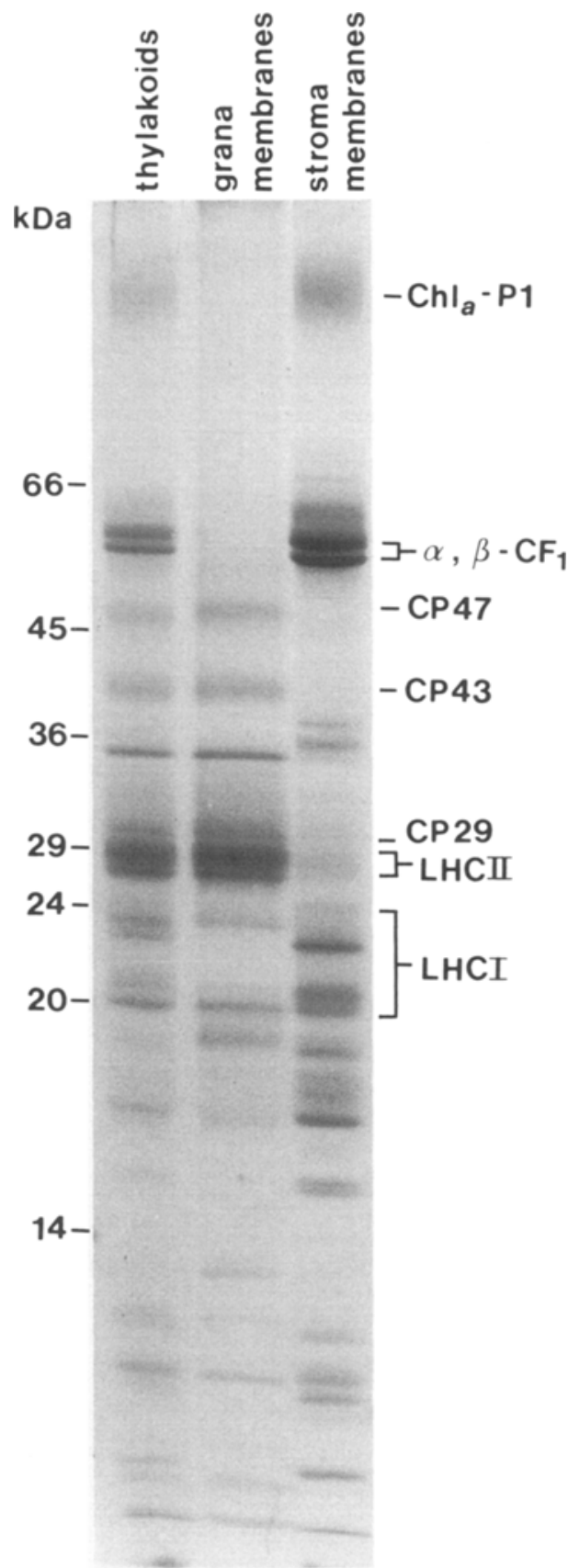

Figure 2. Polypeptide composition of maize stroma membranes compared with grana membranes and whole mesophyll thylakoids. Grana and stroma membranes show an almost perfectly complementary polypeptide composition, with only a few bands with the same mobility in both membrane fractions. 


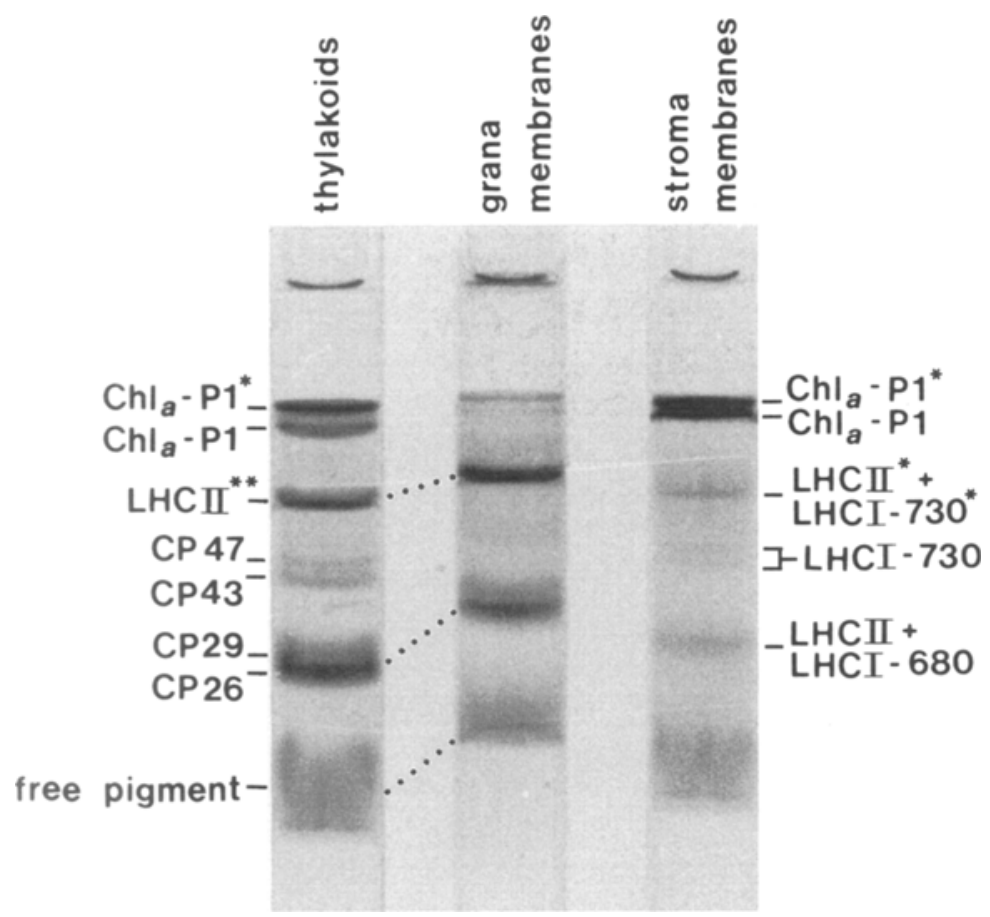

Figure 3. Analysis of chlorophyll-protein content by non-denaturing tube SDS-PAGE at $4{ }^{\circ} \mathrm{C}$. Immediately before electrophoresis, frozen membranes were thawed and solubilised by adding octyl glucoside to $1.5 \%$ and glycerol to $40 \%$ final concentration, with a chlorophyll concentration of $1 \mathrm{mg} \cdot \mathrm{ml}^{-1}$.

PSI is located exclusively in stroma lamellae, and PSII is located mainly in grana membranes, the fluorescence emission spectra show that each membrane fraction is very pure. The purity of the stroma lamellae has also been confirmed by freeze-fracture electron microscopy, which showed a maximum contamination by appressed thylakoids of only $0.1 \%(5)$.

The polypeptide composition of isolated maize stroma lamellae were compared with that of whole mesophyll thylakoids and grana lamellae (Figure 2), on the basis of equal amounts of chlorophyll. A striking feature was the complementary nature of the polypeptide composition of grana and stroma lamellae, with few polypeptide bands common to both. Within the limits of sensitivity of the staining procedure, polypeptides of the PSII core complex appeared to be absent from the stroma membranes, while components of PSI and $\mathrm{CF}_{1}$ were not detectable in appressed grana membranes.
The chlorophyll-protein composition of stroma lamellae was analysed by non-denaturing gel electrophoresis and was compared with that of whole thylakoids and grana membranes. A short electrophoretic run (Figure 3) preserved most of the chlorophyll-proteins, although some were not resolved from one another. The chlorophyllcontaining bands named with an asterisk $\left(^{*}\right)$ refer to chlorophyll-protein complexes consisting of one or more chlorophyll-proteins in a high molecular weight complex, possibly associated with other non chlorophyll-containing polypeptides. Thus LHCII** and LHCI-730* are both homo-oligomers, while $\mathrm{Chl}_{a}-\mathrm{P} 1^{*}$ contains three different chlorophyll-proteins $\left(\mathrm{Chl}_{\alpha}\right.$ P1, LHCI-680 and LHCI-730) and other polypeptides $(8,9)$. These complexes were unstable after prolonged exposure to detergent during a longer electrophoretic run, dissociating into their component chlorophyll-proteins, some of which themselves had a tendency to lose 


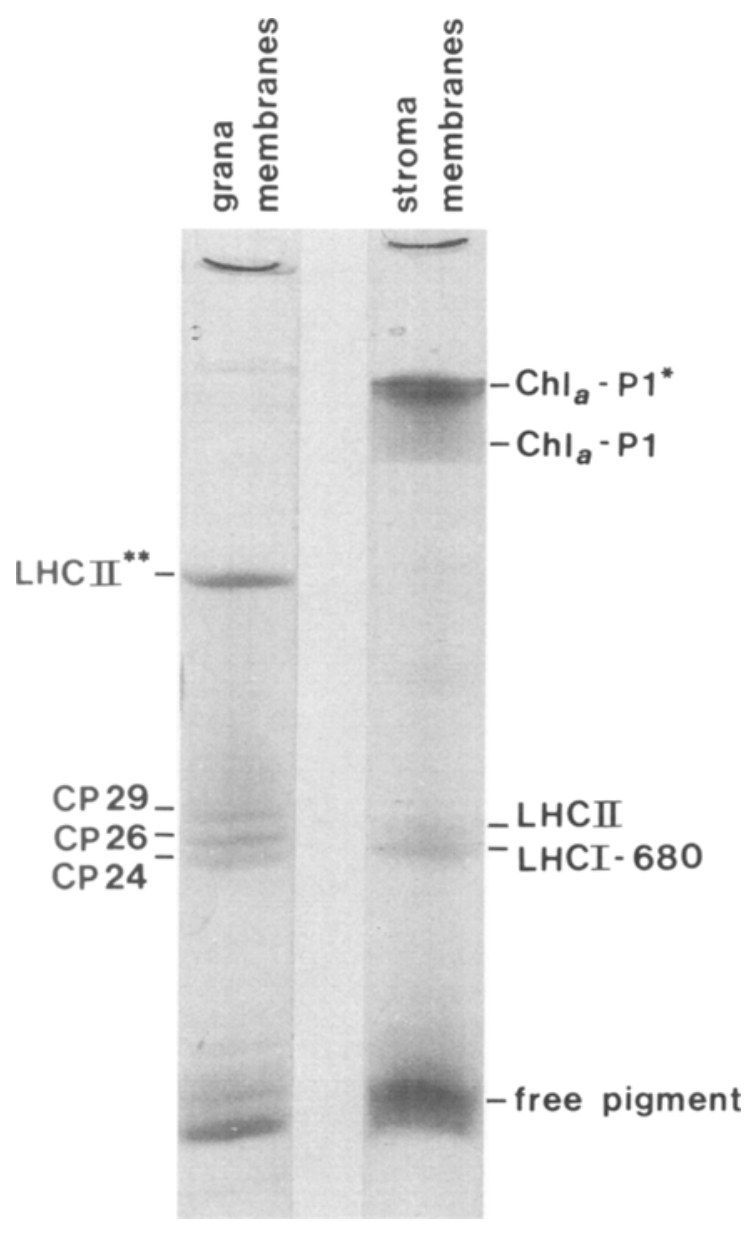

Figure 4. As in Figure 3 after a longer period of electrophoresis. CP24, CP26 and CP29 are clearly resolved in grana membranes and all LHCII is present as the oligomer ( $\mathrm{LHCII}^{* *}$ ), while CP43 and CP47 have disappeared. In stroma lamellae, $\mathrm{LHCII}$ and $\mathrm{LHCI}-680$ are resolved, but $\mathrm{Ch}_{a}-\mathrm{P} 1, \mathrm{LHCII}^{* *}$ and bands containing $\mathrm{LHCI}-730$ are faint or absent.

chlorophyll (Figure 4). Under these conditions, LHCII and LHCI-680 were clearly resolved in stroma membranes, while LHCII**, LHCI-730 and $\mathrm{Chl}_{a}-\mathrm{Pl}$ had lost much of their chlorophyll. In grana membranes, $\mathrm{CP} 24$ and $\mathrm{CP} 26$ appeared as two separate bands in addition to CP29, while CP43 and CP47 had disappeared (Figure 4).

The identity of the chlorophyll-protein complexes in stroma membranes was established from their low temperature fluorescence spectra (Figure 5) and their polypeptide composition (Figure 6). The presence of a $730 \mathrm{~nm}$ peak is characteristic for LHCI-730, and the existence of an oligomeric form with an electrophoretic mobility of $64 \mathrm{kD}$ has previously been reported (9). This chlorophyll-containing band also produced a fluorescence emission peak at $680 \mathrm{~nm}$, indicating that $\mathrm{LHCI}^{* *}$ was co-migrating at this position $(1,19)$.

When the gel slices were cut out and re-electrophoresed under denaturing conditions (Figure 6), co-migrating polypeptides not associated with the chlorophyll-protein complexes were also present (e.g., $\alpha, \beta$ subunits of $\mathrm{CF}_{1}$ in lane 6). 


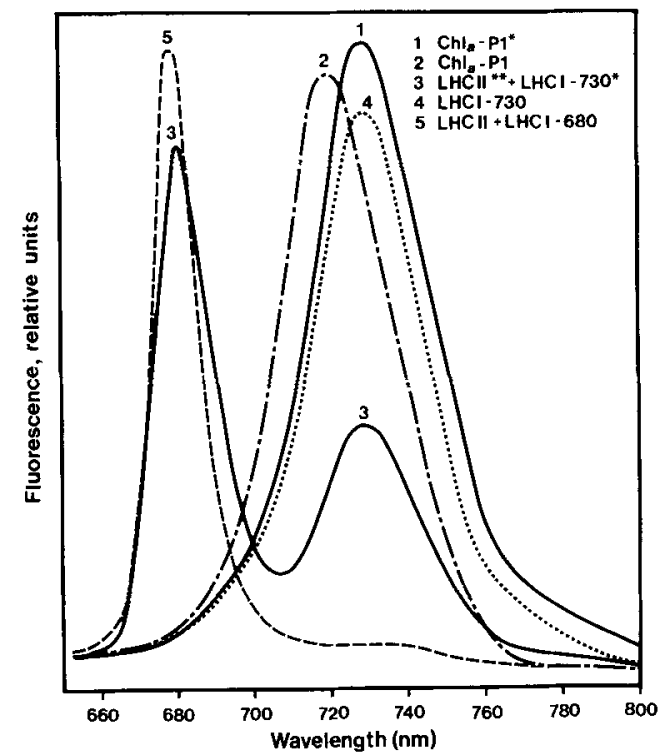

Figure 5. Low temperature $(77 \mathrm{~K})$ fluorescence emission spectra of the chlorophyll-containing bands resolved from the stroma membranes in Figure 3. Immediately after electrophoresis, the green bands were excised, loaded into glass capillary tubes and frozen in liquid nitrogen. The presence of a $730 \mathrm{~nm}$ peak is diagnostic for LHCI-730, while the $680 \mathrm{~nm}$ peak indicates the presence of either LHCII or LHCI-680.

Other polypeptides of much lower molecular weight were either the apo-proteins of the anomalously-migrating chlorophyll-protein(s), or were polypeptides genuinely associated with the complex. Thus, $\mathrm{Chl}_{a}-\mathrm{P} 1$ * contained 8 low molecular weight polypeptides in addition to the apo-proteins of $\mathrm{Chl}_{a}-\mathrm{Pl}$ and LHCI. In addition to confirming the presence of $\mathrm{LHCI}-730$ in lanes $5,6,7$ and 8, LHCI-680 in lane 10, and LHCII in lanes 6 and 9 , three of the low molecular weight polypeptides associated with $\mathrm{Chl}_{a}-\mathrm{Pl}$ * were always present when LHCI-730 was found (asterisks in Figure 6).

The room temperature absorption spectra of the five chlorophyll-containing bands of stroma lamellae are shown in Figure 7. The relative levels of chlorophyll $b$, as estimated from the absorption at 472 and $651 \mathrm{~nm}$, were consistent with the published chlorophyll $a / b$ ratios of the chlorophyll-proteins identified by fluorescence emission spectroscopy and polypeptide composition (9). The chlorophyll-protein compositions of stroma and grana membranes are summarised in Table I.

In whole thylakoids and isolated stroma membranes, mild electrophoresis always produced some monomeric LHCII in the $25-30 \mathrm{kD}$ region (Figure 3), while the oligomeric LHCII** of grana membranes was very stable under the same conditions. The possible role of $\mathrm{Mg}^{++}$in stabilising oligomeric $\mathrm{LHCII}^{* *}$ in stroma lamellae was investigated by resuspending stroma or grana lamellae in buffer containing $5 \mathrm{mM}-\mathrm{MgCl}_{2}$ or $5 \mathrm{~mm}$-EDTA. The presence of $\mathrm{Mg}^{++}$resulted in a significant increase in the amount of oligomeric LHCII** at the expense of monomeric LHCII in stroma membranes (Figure 8). $\mathrm{Mg}^{++}$ions were not required for the stabilisation of LHCII** in grana lamellae.

Since the LHCII in stroma lamellae could have been associated with either PSII or PSI, or both, the amount of PSII in isolated stroma lamellae was determined by immuneblot assay. The labelling intensity of stroma and grana membranes was compared on a chlorophyll basis, and it was clear that stroma membranes contained less than $10 \%$ of the PSII polypeptides found in grana membranes (Figure 9). Extrapolation from a dilution series of grana membranes showed that stroma lamellae contained 30 times less PSII than grana membranes.

Figure 6. Polypeptide composition of chlorophyll-containing bands from stroma lamellae. Excised gel slices were macerated and loaded into the wells of a $6 \mathrm{M}$-urea gel (14-20\% acrylamide). Polypeptides corresponding to LHCII are marked with an arrow, those from LHCI-730 are indicated by a dot, while the arrowhead marks an LHCI-680 polypeptide. The three low molecular weight PSI polypeptides associated with LHCI-730 are indicated with asterisks. 
R. BASSI et al.: Chlorophyll-proteins of stroma lamellae

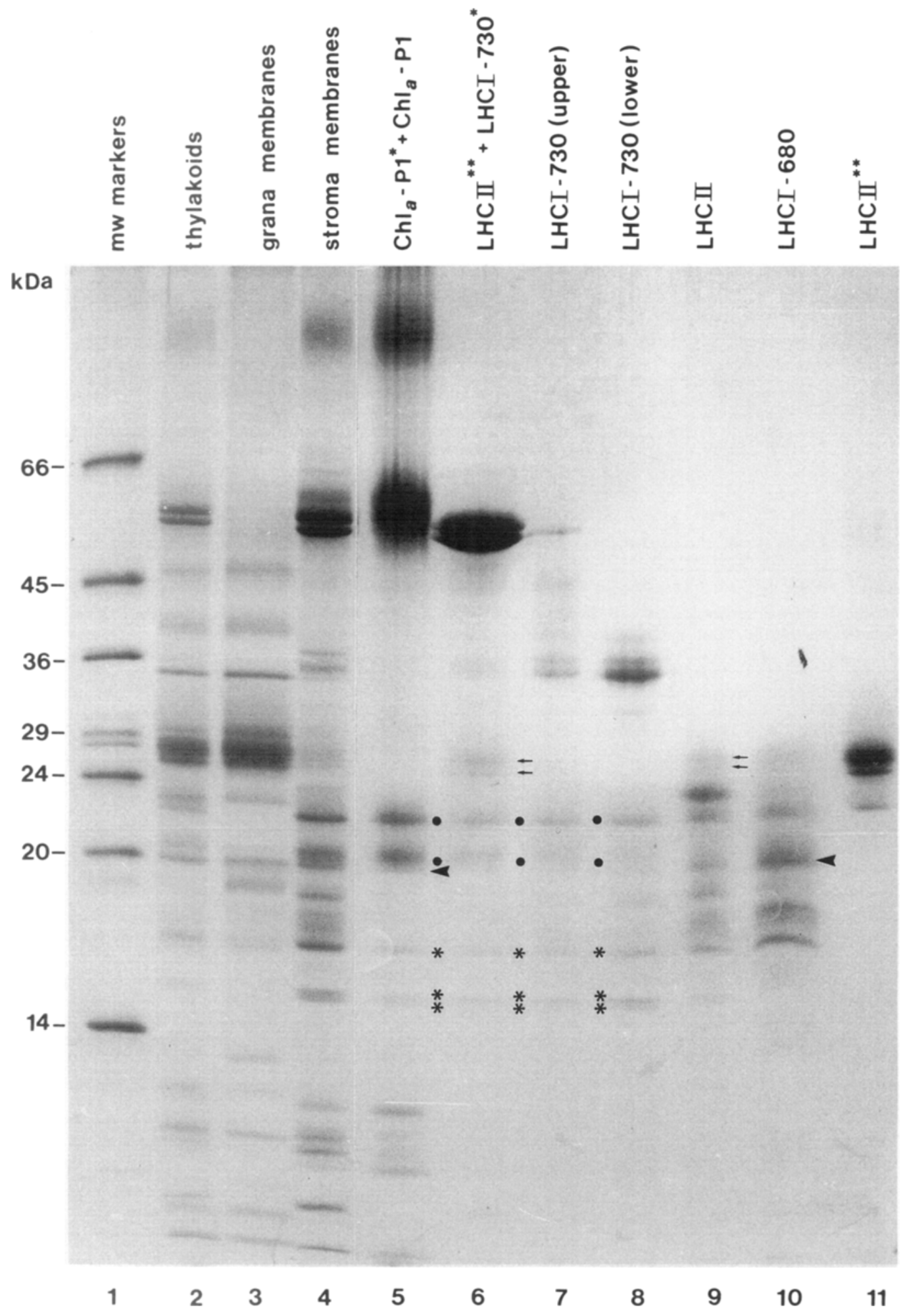




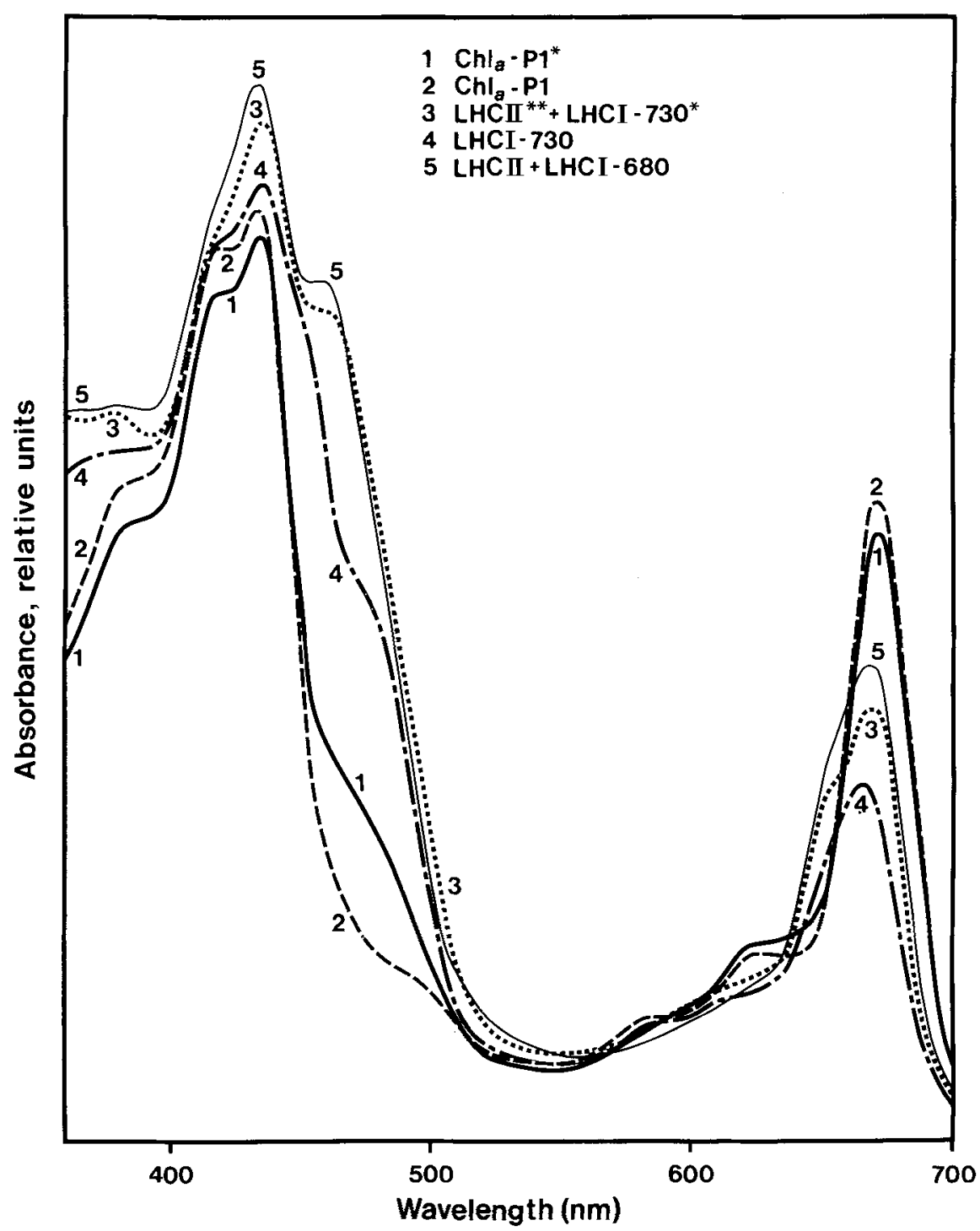

Figure 7. Room temperature absorption spectra of the chlorophyll-containing bands from isolated maize stroma lamellae (see Figure 3). Excised green bands were macerated in distilled water and allowed to elute for $2 \mathrm{~h}$ at $4{ }^{\circ} \mathrm{C}$. Gel pieces were removed by centrifugation and the absorption spectrum of the supernatant recorded at $20^{\circ} \mathrm{C}$.

\section{DISCUSSION}

The organisation of the chlorophyll-proteins of PSI and PSII has been described by BASSI and SIMPSON (9) and BASSI et al. (7), after treatment of thylakoids with the detergent Triton X-100. In the present work, PSI has been enriched by mechanical disruption of thylakoids and isolation of stroma lamellae, thereby avoiding randomisation of thylakoid components due to destacking and the initial Triton $\mathrm{X}-100$ solubilisation. It had previously been shown that LHCII could be induced to associate with PSI by lowering the Triton X-100 concentration during thylakoid solubilisation, raising the possibility that other chlorophyll-proteins, such as LHCI680 , may have become associated with PSI as an artefact of the isolation procedure. It had not been possible to distinguish the LHCI-680 of 
Table I. Chlorophyll-protein composition of stroma and grana lamellae from Zea mays thylakoids.

\begin{tabular}{|c|c|c|c|}
\hline \multicolumn{2}{|l|}{ chlorophyll-protein ${ }^{\S}$} & \multirow[t]{2}{*}{ grana $^{\$ \$}$} & \multirow[t]{2}{*}{ stroma } \\
\hline (a) & (b) & & \\
\hline $\mathrm{Chl}_{a}-\mathrm{P} 2^{*}$ & $\mathrm{CP} 47^{*}$ & + & - \\
\hline $\mathrm{Chl}_{a}-\mathrm{P} 1^{*}$ & CPIa & - & + \\
\hline $\mathrm{Chl}_{a}-\mathrm{Pl}$ & CPI & - & + \\
\hline $\mathrm{Chl}_{a / h}-\mathrm{P} 2^{* *}$ & LHCII** $^{* *}$ & + & + \\
\hline LHCI-730 olig. & LHCI-730* & - & + \\
\hline $\mathrm{Chl}_{a}-\mathrm{P} 2$ & CP47 & + & $+/-$ \\
\hline $\mathrm{Chl}_{a}-\mathrm{P} 3$ & CP43 & + & $+/-$ \\
\hline LHCI-730 mon. & LHCI-730 & - & + \\
\hline $\mathrm{Chl}_{a j h}-\mathrm{Pl}$ & CP29 & + & - \\
\hline $\mathrm{Chl}_{a, h}-\mathrm{P} 2 * *$ mon. & LHCII & + & + \\
\hline $\mathrm{Chl}_{a / h}-\mathrm{P} 2$ & $\mathrm{CP} 26$ & + & - \\
\hline LHCI-680 & CP24 (LHCI-680) & + & + \\
\hline
\end{tabular}

$\$$ listed in order of increasing electrophoretic mobility

$\$ \$$ from Bassi et al. (7)

(a) nomenclature of MACHOLD et al. (19)

(b) nomenclature of CAMM and GREEN (14) and BASSI et al. (7)

+ - present at low levels

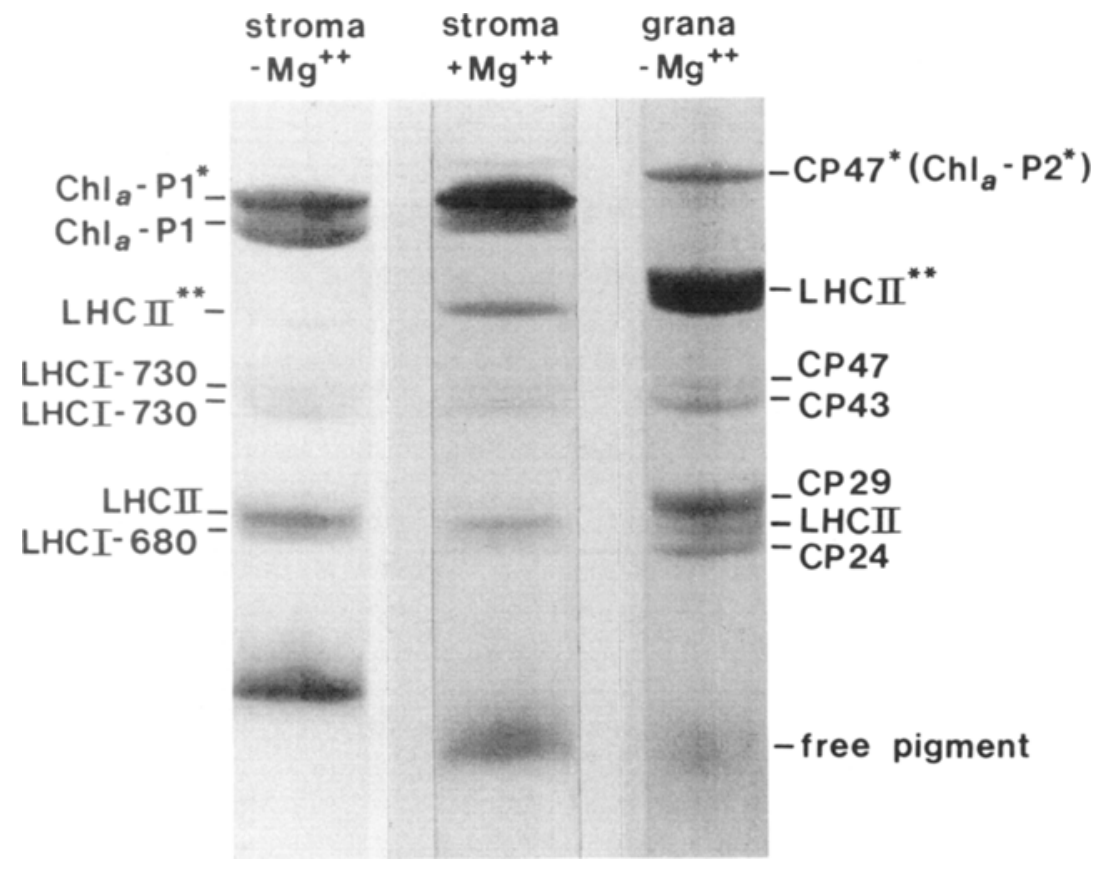

Figure 8. Non-denaturing tube SDS-PAGE of stroma and grana membranes showing the effect of $\mathrm{Mg}^{++}$in stabilising the oligomeric form of LHCII (LHCII**) in stroma lamellae. Samples were prepared as in Figure 3 with the addition of $5 \mathrm{~mm}-\mathrm{MgCl}_{2}\left(+\mathrm{Mg}^{++}\right)$or $5 \mathrm{mM}-\mathrm{EDTA}\left(-\mathrm{Mg}^{++}\right)$before electrophoresis. 
Figure 9. Immuneblot assay for PSII polypeptides. The first two lanes show the polypeptide pattern of grana and stroma lamellae ( $10 \mu \mathrm{g}$ loaded per lane). Polypeptides were electroblotted onto nitrocellulose paper and reacted with antibodies to PSII and ${ }^{125}$ I-labelled protein A. The autoradiograph in lanes 3-5 shows from the relative intensities of the bands at $9 \mathrm{kD}$ (cytochrome $b-559), 17 \mathrm{kD}$ (oxygen evolving complex), $34 \mathrm{kD}$ (D2) and $47 \mathrm{kD}$ (CP47) that stroma lamellae contain less than $10 \%$ of the level found in grana lamellae.

PSI from the CP24 of grana membranes on the basis of electrophoretic mobility, polypeptide composition, spectral properties, or reaction with monoclonal antibodies (7). The presence of significant levels of LHCI-680 in stroma lamellae (Figure 4), demonstrates that its association with PSI is not due to lateral migration from grana appressed membranes. It remains to be established whether CP24 $(7,12)$ and LHCI680 are different chlorophyll-proteins.

The presence of an oligomeric band of LHCI730 has been reported previously (8). We cannot say if this reflects an in vivo association, although analysis of PSI from barley indicates that there is 3 times as much chlorophyll in LHCI730 as in LHCI-680, with probably at least 3 molecules of LHCI-730 per molecule of P700 in the PSI reaction centre (9). This could amount to as many as 6 molecules of LHCI-730 if one assumes 14 molecules of chlorophyll per LHCI polypeptide, as for LHCII. The association of 3 polypeptides with apparent molecular weights of $16.0,13.8$ and $13.5 \mathrm{kD}$ with LHCl-730 (Figure 6) may be related to the existence of the LHCI-730 doublet in Figure 3. It is possible that these 3 polypeptides are closely associated with PSI in situ. It is difficult to compare the different non chlorophyll-containing polypeptides of PSI from one preparation to another since their apparent molecular weight varies according to the gel system used. But, it seems reasonable that the 3 polypeptides associated with LHCI-730 are different from the 18,16 and $14 \mathrm{kD}$ polypeptides associated with $\mathrm{Chl}_{a}-\mathrm{Pl}$ after the removal of LHCI $(13,16,24)$. Of the other low molecular weight polypeptides, with apparent weights of 9.7, 9.2, 8.7, 8.0 and $6.4 \mathrm{kD}$, only the $8 \mathrm{kD} \mathrm{Fe}-\mathrm{S}$ 
protein (16) has a known function, and is tightly bound to $\mathrm{Chl}_{a}-\mathrm{Pl}$.

The presence of significant levels of PSII ( $20 \%$ of total) in stroma lamellae of spinach has been shown $(20,21)$. Its smaller antenna size (21), resistance to photoinhibition (20) and DCMU insensitivity (30), indicate that these reaction centres, called PSII $\beta$, are different from those in grana membranes. The amount of PSII in barley stroma lamellae was found to be much lower than in spinach, at about $8 \%$, and they lack the chlorophyll $a / b$-protein CP29 (30). In maize, another cereal, we have determined that stroma lamellae isolated from mesophyll thylakoids, contain only about $1 / 60$ th, or about $1.7 \%$ of the total PSII (using grana: stroma $=2: 1$ ), based on immunological quantitation of PSII polypeptides (Fig. 9). Assuming from the EFs particle density (25), 1600 PSII reaction centres $/ \mu \mathrm{m}^{2}$ of grana membranes, there would only be 50 PSII reaction centres $/ \mu \mathrm{m}^{2}$ in maize stroma lamellae. This is much less than the EFu particle density $\left(\approx 360 / \mu \mathrm{m}^{2}\right)$, which are thought to represent PSII $\beta$ centres. With 3300 PSI reaction centres/ $\mu \mathrm{m}^{2}$ in stroma lamellae (26), 210 molecules of $\mathrm{Chl} / \mathrm{PSI}(9,21)$ and 60 molecules of $\mathrm{Chl}$ as LHCII/PSII (21), the Chl in LHCII accounts for only $\approx 0.4 \%$ of the total, if it were exclusively associated with PSII $\beta$. There is clearly much more LHCII than this (Figures 3 and 4), so a significant amount of LHCII must be associated with PSI, even though the seedlings had been dark-adapted for $1 \mathrm{~h}$ before isolation. The association of LHCII with PSI in vivo has been shown in the PSII-lacking bundle sheath thylakoids of maize (4), and is responsible in mesophyll thylakoids for the increase in PSI antenna size after state 1 - state 2 transition in vivo (5) and after de-stacking (28).

The instability of oligomeric LHCII** from stroma lamellae in the absence of $\mathrm{Mg}^{++}$is in contrast to that of granal LHCII**. This may be correlated with the absence of the $26 \mathrm{kD} \mathrm{LHCII}$ polypeptide from stroma lamellae (6) and from the "mobile" granal LHCII (5). This $26 \mathrm{kD}$ LHCII polypeptide, which is cleaved by trypsin in isolated LHCII, but not in the membrane (unlike the other LHCII polypeptides) (6), may be important in stabilising the non-covalent bonds between the other LHCII polypeptides.

\section{ACKNOWLEDGEMENTS}

We thank Professor DITER vON WETTSTEIN for his encouragement during the course of this work, and for critically reading the manuscript. We are grateful to Professor BiRger LindBerG MølLER for discussions on the isolation of stroma lamellae. We thank NINA RASMUSSEN for drawing the figures, and ANN-SOFI STEINHOLTZ for printing the photographs.

\section{REFERENCES}

1. ANDERSON, J.M.: P-700 and polypeptide profile of chlorophyll-protein complexes of spinach and barley thylakoids. Biochim. Biophys. Acta 591, 113-126 (1980)

2. ANDERSON. J.M.: Consequences of spatial separation of photosystems 1 and 2 in the thylakoid membrane of higher plant chloroplasts. FEBS Lett. 124, 1-10 (1981)

3. ANDERSSON. B.\& J.M. ANDERSON: Lateral heterogeneity in the distribution of chlorophyll-protein complexes of the thylakoid membranes of spinach chloroplasts. Biochim. Biophys. Acta 593, 427440 (1980)

4. BASSI, R: Spectral properties and polypeptide composition of the chlorophyll-proteins from thylakoids of granal and agranal chloroplast of maize (Zea mays L.). Carlsberg Res. Commun. 50, 127 143 (1985)

5. Bassi, R. G.M. Giacometil \& D.J. Simpson: Changes in the organization of stroma membranes induced by in vivo state 1 - state 2 transition. Biochim. Biophys. Acta, submitted (1988)

6. Bassi, R., F. Rigoni, R. Barbato \& G. Giacometti: Light-harvesting chlorophyll a/b-proteins (LHCII) populations in state 1 - state 2 transition. Biochim. Biophys. Acta, submitted (1988)

7. Bassi, R., G. Høyer-Hansen, R. Barbato, G.M. GIACOMETTI \& D.J. SIMPSON: Chlorophyll-protein complexes of the photosystem II antenna system. J. Biol. Chem. 262, 13333-13341 (1987)

8. Bassi, R., O. Machold \& D.J. SimpSON: Chlorophyll-proteins of two photosystem I preparations from maize. Carlsberg Res. Commun. 50, 145-162 (1985)

9. BASSI, R.\& D.J. SIMPSON: Chlorophyll-protein complexes of barley photosystem I. Eur. J. Biochemistry. 163, 221-230 (1987)

10.BeRTHOLd, D.A, G.T. BABCOCK \& C.F. YoCUM: A highly resolved oxygen-evolving photosystem II preparation from spinach thylakoid membranes. FEBS Lett. 134, 231-234 (1981) 
11. Bricker, T.M., J.G. Metz, D. Miles \& L.A. SherMAN: Biochemical characterization of a highly active $\mathrm{O}_{2}$-evolving photosystem II preparation from maize. Biochim. Biophys. Acta 724, 447-455 (1983)

12. Dunahay. T.G. \& L.A. Staehelin: Isolation and characterization of a new minor chlorophyll $a / b-$ protein complex (CP24) from spinach. Plant Physiol. 80, 429-434 (1986)

13. Goldbeck, J.H., K.G. Parrett, T. Mehari, K.L. JONES \& J.J. BRAND: Isolation of the intact photosystem I reaction center core containing P700 and iron-sulfur center $F_{x}$. FEBS Lett. 228, 268-272 (1988)

14. GreEn. B.R. \& E.L. Camm: The nature of the light-harvesting complex as defined by sodium dodecyl sulfate polyacrylamide gel electrophoresis. Biochim. Biophys. Acta 681, 256-262 (1982)

15. Henry, L.E.A.\& B.L. MøLLER: Polypeptide composition of an oxygen evolving photosystem II vesicle from spinach chloroplasts. Carlsberg Res. Commun. 46, 227-242 (1981)

16. Høנ, P.B. \& B.L. MøLLER: The 110-kDa reaction center protein of photosystem I, P700-chlorophyll a-protein 1, is an iron-sulfur protein. J. Biol. Chem. 261, 14292-14300 (1987)

17. Høyer-Hansen, G., R. BASSi, L.S. Hønberg \& D.J. SIMPSON: Immunological characterization of chlorophyll $\mathrm{a} / \mathrm{b}$-binding proteins of barley thylakoids. Planta 173, 12-21 (1988)

18. Kannangara, C.G., S.P. Gough, B. Hansen, J.N. RASMUSSEN \& D.J. SIMPSON: A homogeniser with replaceable razor blades for bulk isolation of active barley plastids. Carlsberg Res. Commun. 42, 431438 (1977)

19. Machold, O., D.J. Simpson \& B.L. Møller: Chlorophyll-proteins of thylakoids from wild-type and mutants of barley (Hordeum vulgare L.). Carlsberg Res. Commun. 44, 235-254 (1979)

20. Mäenpää, P., B. ANDERSSON \& C. Sundby: Difference in sensitivity to photoinhibition between photosystem II in the appressed and non-appressed thylakoid regions. FEBS Lett. 215, 31-36 (1987)

Accepted by S.O. ANDERSEN
21. MeLis, A. \& J.M. ANDERSon: Structural and functional organization of the photosystems in spinach chloroplasts. Antenna size, relative electron-transport capacity, and chlorophyll composition. Biochim. Biophys. Acta 724, 473-484 (1983)

22. Mullet, J.E., J.J. Burke \& C.J. ARntzen: Chlorophyll proteins of photosystem I. Plant Physiol. 65, 814-822 (1980)

23. SANe, P.V., D.J. Goodchild \& R.B. ParK: Characterization of photosystem I and II separated by a non-detergent method. Biochim. Biophys. Acta 216, 62-178 (1970)

24. SCheller, H.V., P.B. HøJ, I. Svendsen \& B.L. Møller: Partial amino acid sequence of two nuclear-encoded photosystem I polypeptides from barley. Biochim. Biophys. Acta, in press (1988)

25. SIMPSON, D.J: Freeze-fracture studies on barley plastid membranes III. Location of the light-harvesting chlorophyll-protein. Carlsberg Res. Commun. 44, 305-336 (1979)

26. SIMPSON, D.J.: Freeze-fracture studies on barley plastid membranes VI. Location of the P700 chlorophyll a-protein 1. Eur. J. Cell Biol. 31, 305-314 (1983)

27. SIMPSON, D.J.\& B. ANDERSSON: Extrinsic polypeptides of the chloroplast oxygen evolving complex constitute the tetrameric ESs particles of higher plant thylakoids. Carlsberg Res. Commun. 51, 467-474 (1986)

28. Telfer, A., H. Bottin, J. Barber \& P. Mathis: The effect of magnesium and phosphorylation of lightharvesting chlorophyll $\mathrm{a} / \mathrm{b}$-protein on the yield of P-700-photooxidation in pea chloroplasts. Biochim. Biophys. Acta 764, 324-330 (1984)

29. VALLON, O., F.A. WOLLMAN \& J. Olive: Distribution of intrinsic and extrinsic subunits of the PSII protein complex between appressed and non-appressed regions of the thylakoid membrane: An immunocytochemical study. FEBS Lett. 183, 245250 (1985)

30. Vallon, O., G. Høyer-Hansen \& D.J. Simpson: Photosystem II and cytochrome $b-559$ in the stroma lamellae of barley chloroplasts. Carlsberg Res. Commun. 52, 405-421 (1987) 